\title{
Metabolic reprogramming by folate restriction leads to a less aggressive cancer phenotype
}

\author{
Zahra Ashkavand ${ }^{1}$, Ciara O’Flanagan ${ }^{2}$, Mirko Hennig ${ }^{1,2}$, Xiuxia Du $^{3}$, Stephen D. Hursting ${ }^{1,2}$, \\ and Sergey A. Krupenko ${ }^{1,2,{ }^{*}}$ \\ ${ }^{1}$ Nutrition Research Institute, UNC Chapel Hill, Kannapolis, NC \\ ${ }^{2}$ The Department of Nutrition, UNC at Chapel Hill \\ ${ }^{3}$ The Department of Bioinformatics \& Genomics, University of North Carolina at Charlotte
}

\begin{abstract}
Folate coenzymes are involved in biochemical reactions of one-carbon transfer, and deficiency of this vitamin impairs cellular proliferation, migration and survival in many cell types. Here the effect of folate restriction on mammary cancer was evaluated using three distinct breast cancer subtypes differing in their aggressiveness and metastatic potential: non-invasive basal-like (EWnt), invasive but minimally metastatic claudin-low (M-Wnt), and highly metastatic claudin-low (metM-Wnt ${ }^{\text {liver}}$ ) cell lines, each derived from the same pool of MMTV-Wnt-1 transgenic mouse mammary tumors. NMR-based metabolomics was used to quantitate 41 major metabolites in cells grown in folate-free medium versus standard medium. Each cell line demonstrated metabolic reprogramming when grown in folate-free medium. In E-Wnt, M-Wnt and metM-Wnt ${ }^{\text {liver }}$ cells 12 , 29 , and 25 metabolites, respectively, were significantly different ( $p<0.05$ and at least 1.5 -fold change). The levels of eight metabolites (aspartate, ATP, creatine, creatine phosphate, formate, serine, taurine and $\beta$-alanine) were changed in each folate-restricted cell line. Increased glucose, decreased lactate, and inhibition of glycolysis, cellular proliferation, migration and invasion occurred in M-Wnt and metM-Wnt ${ }^{\text {liver }}$ cells (but not E-Wnt cells) grown in folate-free versus standard medium. These effects were accompanied by altered levels of several folate-metabolizing enzymes, indicating that the observed metabolic reprogramming may result from both decreased folate availability and altered folate metabolism. These findings reveal that folate restriction results in metabolic and bioenergetic changes and a less aggressive cancer cell phenotype.
\end{abstract}

Implications-Metabolic reprogramming driven by folate restriction represents a therapeutic target for reducing the burden of breast cancer.

\section{Keywords}

Folate; mammary cancer; metabolome; migration; invasion

\footnotetext{
${ }^{*}$ To whom correspondence should be addressed: Department of Nutrition and Nutrition Research Institute, UNC Chapel Hill, 500 Laureate Way, Kannapolis, NC 28081, sergey_krupenko@unc.edu, Phone: (704) 250-5053.

The authors declare no conflict of interests.
} 


\section{Introduction}

Folate coenzymes participate in biochemical reactions of amino acid conversion and nucleotide biosynthesis and serve as acceptors or donors of one-carbon groups $(1,2)$. Metabolic pathways requiring these coenzymes include the interconversion of serine and glycine, degradation of glycine and histidine, biosynthesis of methionine from homocysteine, and biosynthesis of purine nucleotides and thymidine monophosphate $(1,2)$. Folate metabolism also plays a key role in the clearance of formate generated via several biochemical reactions in the cell $(3,4)$ and in mitochondrial translation initiation (2). Furthermore, folate pathways contribute to cellular energy production through oxidation of carbon groups in folate-dependent reactions $(5,6)$, and folate can serve as an acceptor of formaldehyde during histone demethylation (7). Such diverse roles in metabolic processes make folate indispensable for normal cell function, but it cannot be synthesized by higher animals and must be obtained from dietary sources. Folate deficiency impairs DNA synthesis and repair, changes protein expression patterns and affects numerous methylation reactions that depend on folate for methionine/SAM biosynthesis; these effects will be eventually translated to deregulation of homeostasis, decreased growth rate and inhibition of cell division (8-10).

Metabolic reprogramming is one of hallmarks of cancer (11). Rapidly proliferating cancer cells are especially dependent on an abundant supply of folate to support their metabolic needs for limitless division, including accelerated biosynthesis of nucleotides required for nucleic acids (10). Moreover, folate-dependent serine and glycine synthetic pathways have emerged as crucial for cancer cell proliferation $(12,13)$. Several studies indicate that increased serine synthesis from glucose in cancer cells is a marker of poor prognosis $(14,15)$. Serine derived from this pathway donates carbon groups to the de novo purine and thymidine monophosphate biosynthesis, but it can be also used for ATP production; this folate-dependent pathway involves the conversion of serine to glycine and the glycine cleavage system (16). Metabolic flux through this pathway is upregulated at the level of gene expression in a subset of human tumors and correlates with gene signatures defining cellular proliferation (6).

In addition to supporting cellular proliferation, folate pathways are also required to maintain cellular motility, including folate-dependent regulation of tumor cell migration and invasion (10). Positive correlations between the migratory ability of cancer cells and folate supplementation, as well as the inhibitory effects of antifolates on cancer cell migration, have been demonstrated $(17,18)$. Folate pathways also modulate invasiveness of prostate cancer cells (19) with elevated levels of folic acid promoting both growth and invasiveness of several prostate cancer cell lines (20). Studies from this laboratory have demonstrated that folate regulates motility of A549 human lung cancer cells through an effect on cofilindependent actin dynamics (21). Furthermore, the cofilin-actin axis underlies the inhibition of metastasis and increased survival associated with dietary folate restriction in a lung cancer model in severe combined immunodeficient mice (22). These results are in apparent conflict with findings of an inhibitory effect of increased folate on invasiveness of HCT116 human colon cancer cells via the activation of sonic hedgehog pathways (23). The same study also reported increased migration of HCT116 cell treated with the antifolate methotrexate (23). 
The apparent opposite effect of folate in A549 and HCT116 cells suggests a complex relationship between folate restriction and cancer cell behavior. Since these cells were derived from lung and colon tumors respectively, they are likely to differ in many biological characteristics, including genetic and molecular profiles, metabolic characteristics, stem cell enrichment, invasiveness, and metastatic potential. To better address the biological characteristics contributing to the response to folate restriction, we used a series of cell lines derived from the same tumor that spontaneously arose in MMTV-Wnt-1 transgenic mice. These cell lines, defined as "epithelial (E)-Wnt", "mesenchymal (M)-Wnt", and metastatic M-Wnt to the liver (metM-Wnt ${ }^{\text {liver), }}$ share the same genetic background but vary in terms of molecular profiles, stem cell enrichment, metabolic characteristics and metastatic potential (24). M-Wnt and E-Wnt cells represent claudin-low and basal-like breast tumors, respectively according to their gene expression profiles, and recapitulated these tumors upon orthotopic transplantation into ovariectomized C57BL/6 mice (24). These cells classify with basal-like triple negative breast cancers (TNBCs), which represent $20 \%$ of all breast cancers and have an especially unfavorable prognosis, high metastatic potential, and are refractory to targeted agents. Here we report the effect of folate on proliferation and motility of these cell lines and provide data on alterations in metabolic and protein expression profiles induced by folate restriction.

\section{MATERIALS AND METHODS}

\section{Cell culture and reagents}

Standard ( $2.2 \mu \mathrm{M}$ folic acid) and folate-free RPMI 1640 media were obtained from Invitrogen (Carlsbad, CA). Fetal bovine serum and dialyzed fetal bovine serum were purchased from Atlanta Biologicals (Flowery Branch, GA). Other reagents were from Sigma unless otherwise indicated.

\section{Cell lines}

M-Wnt and E-Wnt cells were derived from spontaneous mammary tumors from MMTVWnt-1 transgenic mice. These cell lines were tested for species verification, karyotyping and genomic instability, and were authenticated by the Molecular Cytogenetics Core facility at the University of Texas MD Anderson Cancer Center (Houston, TX). Metastatic metMWnt ${ }^{\text {liver }}$ cells were derived from a metastatic liver lesion following orthotopic transplantation of previously authenticated M-Wnt cells (24).

\section{Sample preparation for NMR metabolomics}

Cells were grown for $72 \mathrm{~h}$ in $10-\mathrm{cm}^{2}$ plates in either standard or folate-free medium. Plates at about $80 \%$ confluence were placed on ice, media removed and cells washed three times with ice cold PBS. After addition of $1.0 \mathrm{ml}$ acetonitrile chilled to $-20{ }^{\circ} \mathrm{C}$ and $750 \mu \mathrm{l}$ ice cold $\mathrm{H}_{2} \mathrm{O}$, cells were harvested by scraping and transferred into $15 \mathrm{ml}$ polystyrene tube. This step was repeated using the same volume of acetonitrile/water to ensure that maximal number of cells was collected. After addition of $1.0 \mathrm{ml}$ chloroform chilled to $-20{ }^{\circ} \mathrm{C}$ and three small glass beads ( $3 \mathrm{~mm}$ diameter), cells were vigorously shaken using a vortex mixer and then centrifuged in swinging bucket rotor (3000xg for $20 \mathrm{~min}$ at $4{ }^{\circ} \mathrm{C}$ ). The top aqueous layer was carefully transferred to $1.5 \mathrm{ml}$ microcentrifuge tubes and lyophilized. The middle layer was 
collected, dried using a SpeedVac, and the resultant pellet was weighted to assess the total amount of protein. All conditions were collected in triplicate.

\section{NMR spectroscopy}

Sodium phosphate buffer solution was prepared by dissolving $1,442.5 \mathrm{mg}$ of $\mathrm{NaH}_{2} \mathrm{PO}_{4}$ and $262.5 \mathrm{mg}$ of $\mathrm{Na}_{2} \mathrm{HPO}_{4}$ in $100 \mathrm{~g}$ of $\mathrm{D}_{2} \mathrm{O}$ and used without further $\mathrm{pH}$ correction (uncorrected $\mathrm{pH}$ meter reading 7.59; $100 \mathrm{mM}$ final concentration). Water-soluble metabolite extracts were diluted in $550 \mu$ of buffer containing trimethylsilylpropanoic acid (1.0 mM final concentration). All samples were briefly vortexed and centrifuged for $2 \mathrm{~min}$ at 14,000 rpm at room temperature and $500 \mu \mathrm{l}$ of the resulting supernatant was subsequently transferred to 5 mm tubes (Bruker-Biospin Corporation, Billerica, MA) for NMR analysis. All ${ }^{1} \mathrm{H}$ - and ${ }^{13} \mathrm{C}$ NMR experiments were performed at 298K on either Bruker Avance II 800 or $600 \mathrm{MHz}$ spectrometers equipped with cryogenically cooled, triple resonance inverse (TCI) and dual resonance $\left({ }^{13} \mathrm{C}\right.$-optimized) DCH cryoprobes with actively shielded Z-gradients, respectively. One-dimensional ${ }^{1} \mathrm{H}$ spectra of the diluted cell extracts were collected using a Carr-PurcellMeiboom-Gill (CPMG) pulse sequence. All 1D experiments employed low-power presaturation to suppress residual water. Typically, $1 \mathrm{D}-{ }^{1} \mathrm{H}$ NMR spectra with a $7 \mathrm{~s}$ recycle delay were acquired with a total of 128 transients in addition to 8 dummy scans. A total of 32768 real data points were collected across a spectral width of $15 \mathrm{ppm}$ (acquisition time: $3.6 \mathrm{~s}$ ). Data were zero-filled to twice the original data set size, manually phased and automatically baseline corrected using Topspin 3.1 software (Bruker Biospin Corporation) and the Chenomx NMR suite (version 8.0) program (Chenomx Inc. Edmonton, AB), respectively. A $0.3 \mathrm{~Hz}$ line-broadening apodization was applied prior to spectral analysis.

\section{NMR data analysis}

The singlet produced by the known quantity of the TSP methyl groups was used as an internal standard for chemical shift referencing (set to $0 \mathrm{ppm}$ ) and for quantification. A targeted metabolite profiling was carried out using the Chenomx NMR suite program (Chenomx Inc. Edmonton, AB). All spectra were imported into the Chenomx profiling software and concentrations of 41 metabolites were determined. After reference deconvolution was applied based on the $1 \mathrm{mM}$ internal TSP standard line shape, absolute concentrations were determined. Concentrations are expressed as the mean \pm standard deviation (SD) of the mean. Statistical significance was determined using Student's t-test without assuming a consistent SD. A p-value of $<0.05$ was considered significant.

\section{Western blot and dot blot assays}

Cells were lysed in RIPA buffer containing protease inhibitors cocktail (Sigma). Lysates were normalized by the level of total protein and analyzed by SDS-PAGE followed by immunoblot with corresponding antibodies. 5-Aminoimidazole-4-carboxamide ribonucleotide formyltransferase (AICART), 10-formyltetrahydrofolate dehydrogenase (ALDH1L1), phosphoribosylglycinamide formyltransferase (GART), glycine Nmethyltransferase (GNMT) and cytoplasmic $\mathrm{C}_{1}$-synthase (MTHFD1) were detected using in-house polyclonal antibodies (1:10000) (25-27). Polyclonal antibodies against thymidylate synthase (THYMS) and cytosolic serine hydroxymethyltransferase (SHMT1) (both from Cell Signaling Technology, 1:1000) and dihydrofolate reductase (DHFR) (Abcam, 1:1000) 
were used. Polyclonal antibodies against methionine synthase (MTR) (1:1000) were from Thermo Fisher. Actin monoclonal antibody (1:5000) was from Sigma.

\section{Cell proliferation assay}

Cell viability was assessed using an MTT cell proliferation assay (Promega). Cells were plated at a density of $5 \times 10^{3}$ cells/well in 96-well format, and MTT was added at specified time points. Plates were further processed according to the manufacturer's instructions. Absorbance at $570 \mathrm{~nm}$ was read using a Wallace 1420 multilabel counter (PerkinElmer Life Sciences).

\section{Measurements of lactate and glucose}

L-lactate levels were measured in cell lysate and medium using a Lactate Colorimetric Assay Kit (Abcam, Cambridge, MA) according to manufacturer's instructions. Glucose levels in cell lysate were measured using Glucose Colorimetric Assay Kit (Abcam) according to manufacturer's instructions. In these experiments, cells were grown in standard or folate-free medium for $0-72 \mathrm{~h}$. All experiments were repeated at least two times. Data were normalized to final cell counts.

\section{Transwell invasion assay}

Invasion assays were carried out using inserts precoated with extracellular matrix, and the Cell Invasion Assay Kit (Chemicon) according to the manufacturer's protocol. Cells were kept in standard or folate-free medium for $72 \mathrm{~h}$ and then seeded into the upper chamber of a Transwell insert (BD Bioscience) in serum-free medium at a density of $5 \times 10^{4}$ cells/well. Medium containing $10 \%$ FBS was placed in the lower chamber as a chemoattractant, and cells were incubated for $24 \mathrm{~h}$ at $37{ }^{\circ} \mathrm{C}$ in $\mathrm{CO}_{2}$ incubator. Nonmigrating cells were removed from the upper chamber by scraping; the remaining cells were stained with Diff-Quick dye (Dade Behring, Inc.). Stained cells were counted in 10 random microscopic fields in three independent inserts. Alternatively, stained cells were lysed with 10\% acetic acid (100-200 $\mu \mathrm{l} /$ well) and quantified by absorbance at $560 \mathrm{~nm}$. In experiments with replete medium, cells were grown in folate-free medium for $72 \mathrm{~h}$ and then in medium with $2.2 \mu \mathrm{M}$ folic acid for 72 h.

\section{Wound healing assay}

Cells $\left(3.5 \times 10^{4}\right.$ cells in $\left.70 \mu \mathrm{l}\right)$ were seeded in 35 - $\mathrm{mm} \mu$-Dish culture inserts (ibidi $\mathrm{GmbH}$, Munich, Germany) and cultured for $24 \mathrm{~h}$ in standard or folate-free medium. Inserts were removed and images of the denuded area were taken at $0,12,24$ and $48 \mathrm{~h}$ using an inverted microscope (Carl Zeiss, 5x magnification).

\section{Real-time cell analysis (RTCA)}

Experiments were carried out using an xCELLigence RTCA DP instrument (ACEA Biosciences, San Diego, CA) placed in a humidified incubator at $37^{\circ} \mathrm{C}$ and $5 \% \mathrm{CO}_{2}$ according to manufacturer's manual. Cell proliferation was monitored using E-plate 16 (ACEA Biosciences). The background impedance reading for each well was set up using cell-free medium ( $100 \mu \mathrm{l}$ per well) after pre-incubation at room temperature for $30 \mathrm{~min}$. 
Cells were seeded in each well in $100 \mu \mathrm{l}$ cell suspensions across a concentration range of $5 \times 10^{3}$ to $80 \times 10^{3}$ cell/well and allowed to attach for $30 \mathrm{~min}$ at room temperature. Plates were locked in the instrument and impedance readings of each well were automatically recorded every $15 \mathrm{~min}$ for the duration of the experiment. Cell migration experiments were performed using two-chamber CIM-plate 16 (ACEA Biosciences). The background reading was set up in the absence of cells after adding serum-free RPMI 1640 medium (50 $\mu \mathrm{l})$ in the upper chamber and 10\% serum-containing RPMI 1640 medium $(150 \mu \mathrm{l})$ in the lower chamber and incubating plates in the instrument for $60 \mathrm{~min}$. Cells $\left(40 \times 10^{3}\right.$ in $\left.100 \mu \mathrm{l}\right)$ kept on FBS-free medium for 24 hours were seeded in the upper chamber and incubated for $30 \mathrm{~min}$ at room temperature. Reading was performed as for the proliferation assay.

\section{Metabolic flux analysis}

Bioenergetics of cells in the presence or absence of folate was determined using the Seahorse XF96 Analyzer (Agilent Seahorse Technologies, Santa Clara, CA). Cells were seeded at a concentration of $1 \times 10^{3}$ or $5 \times 10^{3}$ cell/well and kept in standard or folate-free media for $24 \mathrm{~h}$ or $48 \mathrm{~h}$. Prior to measurement, cells were incubated with standard or folatefree RPMI 1640 medim supplemented with $2 \mathrm{mM}$ glutamine, $10 \mathrm{mM}$ glucose and $1 \mathrm{mM}$ sodium pyruvate and incubated for $1 \mathrm{~h}$ at $37^{\circ} \mathrm{C}$ in a $\mathrm{CO}_{2}$-free atmosphere. Basal oxygen consumption rate (OCR) (indicative of mitochondrial respiration) and extracellular acidification rate (ECAR) (indicative of lactic acid extrusion following glycolysis) were measured. OCR and ECAR responses following administration of oligomycin $(1 \mu \mathrm{M})$, carbonyl cyanide-4-(trifluoromethoxy)phenylhydrazone (FCCP) $(1 \mu \mathrm{M})$, and a combination of antimycin $(3 \mu \mathrm{M})$ and rotenone $(3 \mu \mathrm{M})$ (XF Cell Mito Stress Test Kit, Agilent Seahorse Technologies). For glycolysis analysis, cells were incubated as above without glucose or sodium pyruvate and measurements were taken following administration of glucose (10 $\mathrm{mM})$, oligomycin $(1 \mu \mathrm{M})$ and 2-deoxyglucose $(50 \mathrm{mM})$ (XF Glycolysis Stress Test, Agilent Seahorse Technologies). Results were normalized using a bicinchoninic acid (BCA) protein assay (Thermo Fisher, Waltham MA). All experiments were performed in sextuplicate.

\section{Statistical analysis}

Standard errors were calculated using Microsoft Excel or GraphPad Prism. GraphPad Prism was used to calculate $p$ values. Principal component analysis (PCA) was carried out in the programming language $\mathrm{R}$ to reduce the dimension of the metabolic profile of each cell line. The first two principal components, i.e. PC1 and PC2, are displayed. In the PCA analysis, the cell line data was first mean-centered and subsequently the PCs were computed. The mean-centered data was not further scaled to obtain the $z$-score before the computation of the PCs.

\section{RESULTS}

\section{Levels of major metabolites in Wnt cells}

We performed targeted metabolic profiling of E-Wnt, M-Wnt and metM-Wnt ${ }^{\text {liver }}$ cells using NMR spectroscopy. This approach allowed us to detect and identify 41 major metabolites, including 15 common amino acids (Table 1). The number of analyzed metabolites in these experiments was limited essentially by the sensitivity of the NMR-based detection, which 
was about $1 \mu \mathrm{M}$, in combination with the regional complexity of the NMR spectrum. Principal Component Analysis (PCA) was carried out to compare metabolic profiles of three cell lines. This mathematical method allows evaluation of differences between large data sets (levels of 41 compounds for each cell line in our case) upon the reduction of variables to a smaller number ("principal components") and is commonly used for the analysis of metabolomic data $(28,29)$. PCA has shown that, based on the overall metabolic signature, samples from the three cell lines are well segregated indicating that these cell lines are metabolically different (Fig. 1A). Most differences were between the epithelial E-Wnt cell line and the two mesenchymal cell lines (M-Wnt and metM-Wnt ${ }^{\text {liver }}$ ). Levels of eight metabolites (4-aminobutyrate, aspartate, creatine phosphate, glucose, $\mathrm{NAD}^{+}$, proline, taurine, and $\beta$-alanine) were approximately two-fold or more higher and levels of two metabolites, glycine and putrescine, were approximately two-fold lower in E-Wnt cells compared to M-Wnt or metM-Wnt cells (Table 1). In addition, levels of ATP, NAD ${ }^{+}$and $\mathrm{NADP}^{+}$were higher in the E-Wnt cells relative to M-Wnt or metM-Wnt ${ }^{\text {liver }}$ cells (Table 1).

\section{Alterations in major metabolites in response to folate restriction}

Significant changes in response to folate restriction were observed in each of the cell lines with generally stronger effects on mesenchymal cells than epithelial cells (Table 1). PCA performed for metabolic profiles of cells growing in standard (control) versus folate-free medium demonstrated clear and strong treatment-dependent segregation in each case (Fig. 1B), which we interpreted as metabolic reprogramming. Statistically significant changes $(\mathrm{p}<0.05)$ in levels of 12 metabolites occurred in E-Wnt cells as compared with 29 and 25 metabolites, respectively, in M-Wnt and metM-Wnt ${ }^{\text {liver }}$ cells (Table 1). Eight metabolites (aspartate, ATP, creatine, creatine phosphate, formate, serine, taurine and $\beta$-alanine) were changed in all cell lines, with five of them (aspartate, ATP, creatine, serine and taurine) altered in the same direction in each cell line (Table 1). Between M-Wnt and metM-Wnt liver cells, 22 metabolites were commonly changed with 20 of them altered in a similar way (up or down) and two metabolites (creatine phosphate and $\beta$-alanine) changed differently (Table 1 and Fig. 1C).

Statistically significant elevations in serine and myo-inositol, and reductions in creatine and taurine, were detected in all cell lines after folate restriction (Table 1 and Fig. 1C). Taurine and serine were changed to about the same extent in all cells; changes in myo-inositol were less prominent in E-Wnt cells while levels of creatine decreased more in E-Wnt cells than in M-Wnt or metM-Wnt ${ }^{\text {liver }}$ cells (Table 1 and Fig. 1C). Most amino acids with the exception of glycine were elevated in cells grown on folate-free media (Table 1 and Fig. 1C). This trend had a higher magnitude in two mesenchymal cell lines (Fig. 1C). In mesenchymal cells, strong accumulation of glucose was observed with concomitant drop in lactate upon folate restriction, while levels of glucose was not changed in epithelial cells with only marginal decrease of lactate levels (Table 1 and Fig. 1C). Overall, clustering of samples after PCA has shown that following folate restriction both mesenchymal cell lines were very different metabolically from epithelial E-Wnt cells but were indistinguishable from each other (Fig. 1A). 


\section{Changes in folate enzymes}

Using Western blot assays, we evaluated changes in levels of several key folate enzymes in response to folate starvation. No noticeable increase in the levels of any of tested folate enzyme was observed while cell type-specific down regulation of several targets was apparent after folate withdrawal (Fig. 2A). Levels of several enzymes were not changed in Wnt cells, including TYMS, MTR, and the folate-dependent enzyme in the de novo purine biosynthesis, AICART (Fig. 2A). Another folate-dependent enzyme in the de novo purine pathway, GART, was noticeably down-regulated in each cell line (Fig. 2A). Dihydrofolate reductase (DHFR), the key enzyme to convert dietary folic acid to tetrahydrofolate, was down-regulated in mesenchymal type cells (M-Wnt and metM-Wnt ${ }^{\text {liver }}$ ) but not epithelial EWnt (Fig. 2A). Conversely, strong decreases in levels of MTHFD1 and SHMT1 were observed in E-Wnt cells with no changes for the latter protein and marginal changes in the former protein in M-Wnt and metM-Wnt ${ }^{\text {liver }}$ cells (Fig. 2A). Two folate enzymes, ALDH1L1 and GNMT, were not detected in any of the three cell lines (Fig. 2A), which is in agreement with the reported ubiquitous loss of these proteins in malignant tumors $(25,27)$. Western blot data were confirmed by dot-blot assays (Supplementary Fig. 1), which allows a more robust assessment of proteins levels using triplicates of multiple sample dilutions to both increase accuracy and ensure that observed differences were not the result of sample variations. Reactions catalyzed by corresponding enzymes are depicted in Fig. 2B.

\section{Metabolic flux analysis}

Alterations in intracellular glucose and lactate levels in response to folate restriction were assessed using colorimetric assays and indicated the impairment of glycolysis. In cells maintained in a standard culture medium, both intracellular and extracellular levels of lactate increased in time-dependent manner (Fig. 3). In contrast, both intracellular and extracellular lactate levels were decreased if cells were cultured in folate-free media (Fig. 3). Likewise, compared to cells grown in control (standard) media, glucose levels were increased in MWnt and metM-Wnt ${ }^{\text {liver }}$ (but not E-Wnt) cells grown in folate-free medium (Fig. 3). These results were consistent with NMR metabolomic profiling experiments (Table 1 and Fig. 1C). We further used a Seahorse metabolic analyzer to examine metabolic flux in cells grown in standard or folate-free medium. We observed that folate depletion resulted in significantly decreased oxygen consumption rate (OCR) in E-Wnt, M-Wnt and metM-Wnt ${ }^{\text {liver }}$ cell lines (Fig. 4). Inhibition of ATP synthase with oligomycin (mitochondrial stress test) and incubation with mitochondrial uncoupler FCCP demonstrated that folate depleted cells display reduced ATP production and reduced maximal mitochondrial respiration, as well as reduced respiratory capacity (the difference between maximal and basal OCR) (Fig. 4). Folate restriction also caused a significant reduction in glycolysis, as measured by extracellular acidification rate (ECAR) following stimulation with glucose (Fig. 4). In addition, all cell lines displayed reduced maximal glycolysis rate following incubation with oligomycin, and decreased glycolytic reserve (the difference between maximal and glucose stimulated ECAR) (Fig. 4). Overall, our data indicated the impairment of both mitochondrial respiration and glycolysis upon folate withdrawal from culture medium. Of note, the effect of folate restriction was stronger in $\mathrm{M}-\mathrm{Wnt}$ and metM-Wnt ${ }^{\text {liver }}$ cells than in E-Wnt cells (Fig. 4). 


\section{Proliferation and migration of Wnt cells}

To investigate how the observed metabolic reprogramming following folate restriction influences cellular behavior, we evaluated the effect of folate withdrawal on cellular proliferation, invasion and migration. All three tested cell lines, E-Wnt, M-Wnt and metMWnt ${ }^{\text {liver }}$ were sensitive to the loss of folate: proliferation was essentially arrested by $48 \mathrm{~h}$ of folic acid withdrawal from the media (Fig. 5A). Significant cell death was observed if cells were cultured without folate for more than $72 \mathrm{~h}$ (data not shown). As assessed by the transwell assay, folate restriction ( $72 \mathrm{~h}$ in folate-free medium) strongly inhibited cell invasion with a more profound effect observed in M-Wnt cells than either E-Wnt or metMWnt ${ }^{\text {liver }}$ cells (Fig. 5, B and C). This inhibitory effect was reversible upon repletion of cell culture medium with folic acid (Fig. 5, B and C). Wound healing scratch assays further indicated that the migration of Wnt cells was strongly inhibited in the absence of folate (Supplementary Fig. 2). We have also measured cellular migration using impedance-based ACEA technology (30). The setup in this approach corresponds to the conventional transwell assay but allows the constant monitoring of migration in real time and minimizes the input of cell proliferation. The real-time monitoring of cellular migration confirmed that folate restriction more strongly affected migration of cells with mesenchymal (M-Wnt and metM-Wnt ${ }^{\text {liver }}$ ) relative to epithelial (E-Wnt) phenotype (Fig. 5, D-F). Similar to invasion, the effect of folate restriction on migration was reversible: cells restored their proliferation and migration capacity after folate in medium was replete (data not shown).

\section{DISCUSSION}

Folate is involved in several major metabolic processes (Fig. 2B), and modulation of folate levels has a pleiotropic effect on the cell, directly or indirectly influencing levels of numerous metabolites (pathways connecting folate metabolism to metabolites altered in our study are depicted in Fig. 6). Targeting folate metabolism using antifolates such as methotrexate and aminopterin was one of the earliest cancer chemotherapeutic approaches (31). However, antifolates, and more recently specific inhibitors aimed at counteracting upregulation of key biosynthetic/salvage enzymes involved in folate metabolism, are typically quite toxic and prone to inducing tumor cell resistance (31). Folate restricted diets have been suggested as a possible alternative to pharmacologic antifolate agents, but the limited studies to date regarding breast cancer have shown both enhancing and inhibitory effects of low-folate diets and suggest factors such as tumor stage and molecular subtype can influence the effect of folate restriction on breast cancer. To begin to deconvolute the complex relationship between folate restriction and breast cancer, we assessed folate restriction effects on mammary cancer cell lines (derived from MMTV-Wnt-1 transgenic mouse mammary tumors) with differential metastatic potential and molecular characteristics. Cells representing basal-like (epithelial type E-Wnt cell line) and claudin-low (mesenchymal M-Wnt and metM-Wnt ${ }^{\text {liver }}$ cell lines) breast tumors were analyzed. We found that folate-free medium, compared to standard medium containing $2.2 \mu \mathrm{M}$ folic acid, induced changes in several metabolites (serine, glycine, histidine, formate and taurine) and decreased some key folate enzymes involved in metabolism of serine, glycine and formate and supporting the flux of one-carbon groups to the intracellular folate pool. Significant changes in levels of glucose and several metabolites derived from glucose were observed in mesenchymal (M- 
Wnt and metM-Wnt ${ }^{\text {liver }}$ ) cells but not in epithelial E-Wnt cells. Folate restriction also strongly inhibited glycolysis in M-Wnt and metM-Wnt ${ }^{\text {liver }}$ cells in association with inhibition of cellular proliferation, migration and invasion. Overall, our findings indicated that folate restriction can initiate cell type-specific metabolic reprogramming of breast cancer cells towards a less aggressive phenotype.

Based on metabolic pathways of folate $(1,2)$, the immediate downstream effects of altered levels of folate should be on serine, glycine, histidine, methionine, homocysteine, formate and nucleotides (Fig. 2B). Interestingly, we have observed that overall levels of amino acids in folate-starved cells are increased, though this increase is marginal in E-Wnt cells (Fig. 1C). We have interpreted this effect as an indication of decreased protein synthesis, consistent with the antiproliferative effect of folate restriction observed in the three studied cell lines. While levels of most amino acids were elevated upon folate restriction, levels of glycine were only marginally elevated in M-Wnt cells but decreased in two other cell lines. This finding is in agreement with the deficiency of folate coenzymes, which would prevent the generation of glycine from serine. It should be noted that the consumption of extracellular glycine is not sufficient to support metabolic needs of cancer cells (32). Furthermore, strong elevation of serine, as well as the elevation of histidine and formate (Table 1 and Fig. 1C), fit the signature of folate deficiency. The drop in ATP observed in folate-starved cells conforms with recent findings that folate pathways contribute to cellular energy production $(5,6)$. This ATP reduction was less profound in E-Wnt cells, possibly due to input of activated phosphate groups from creatine phosphate. Indeed, a significant decrease in creatine phosphate upon folate withdrawal was measured in E-Wnt cells but not M-Wnt or metM-Wntliver cells (Table 1). While the replenishment of ATP by creatine phosphate is a well-known phenomenon, the capacity of this process in M-Wnt and metMWnt ${ }^{\text {liver }}$ cells might be insufficient due to low levels of creatine phosphate in these cells.

Levels of several metabolites not directly relevant to folate pathways were significantly changed upon folate restriction. Of particular interest was the drop in lactate with simultaneous elevation of glucose, a phenomenon observed only in mesenchymal M-Wnt and metM-Wnt ${ }^{\text {liver }}$ cells but not E-Wnt cells. In many tumor types high lactate production and concentration have been associated with increased migratory ability and invasiveness of cancer cells, more aggressive cancer stages, and metastasis $(33,34)$. While changes in metabolites not associated directly with folate metabolism could be a consequence of inhibited proliferation, at least in case of lactate our results suggest otherwise. Thus, strong difference in levels of lactate between cells grown in standard versus folate-free medium were recorded at time points when proliferation was not yet arrested (compare Figs. 3 and $5 \mathrm{~A})$.

One advantage of a high glycolytic rate in cancer cells is the acidification of the tumor microenvironment by lactate extrusion, which is associated with higher proliferation, migration and invasion, angiogenesis and increased cell survival (35). For example, the decrease of lactate production by knocking down lactate dehydrogenase inhibits migration and invasion of $4 \mathrm{~T} 1$ breast cancer cells (36). Similar effects were demonstrated in several cancer cell lines by targeting lactate transporters $(37,38)$. Lactate may also serve as a signaling molecule in breast cancer regulating nutrient uptake and potentially cell viability, 
proliferation and migratory capacity (39). In addition, through the conversion to pyruvate lactate can be used for energy generation, particularly in breast tumors $(33,40)$. Thus, within the same tumor, lactate produced by glycolytic tumor cells can be consumed by oxidative tumor cells for the energy generation (41). In our study the drop in lactate in folate-deficient cells was not associated with increased lactate excretion since the extracellular concentrations of this metabolite were also significantly decreased. While such a drop could be associated with enhanced lactate utilization for the energy production, the accumulation of glucose in folate-deficient cells was in agreement with the decreased lactate generation. Likewise, metabolic profiling using Seahorse technology indicated reduced glycolytic capacity in folate-starved cells with stronger effect on mesenchymal (M-Wnt and metM$\mathrm{Wnt}^{\text {liver}}$ ) cells.

In recent years numerous studies have attempted to use metabolomic data to define a signature for tumorigenic potential of different malignancies, including breast tumors (42). Lactate, taurine, glucose and myo-inositol have been linked with tumor aggressiveness, although precise associations between their levels and disease need further clarification $(34,42,43)$. Interestingly, changes of these four metabolites in folate deficient versus folate supplemented M-Wnt and metM-Wnt ${ }^{\text {liver }}$ cells (Fig. 1C) mirror the pattern of their alterations in colorectal cancer, where glucose and myo-inositol are decreased while lactate and taurine are increased compared to normal tissues (34). Specifically to myo-inositol, it has been also reported that this metabolite was significantly increased in breast cancer survivors who underwent chemotherapy (44) and in healthy control subjects compared to men with prostate cancer (45). These findings suggest that the drop in myo-inositol levels is a common trend in malignancies. Accordingly, significantly increased levels of myo-inositol in folate-restricted cells imply a shift towards less aggressive phenotype, which is in agreement with the loss of migratory and invasive ability in these cells. While it is unclear how folate restriction results in the elevation of myo-inositol, this elevation was accompanied by an elevation of glucose, the substrate for myo-inositol biosynthesis (46). Levels of taurine, which in our study significantly decreased with folate restriction, have been used in several studies as a tumor marker $(43,47-49)$. Relevant to our study, levels of taurine increased in breast cancer biopsies (50) yet decreased in MCF-7 breast cancer cells treated with curcumin, a compound with known antiproliferative activity (51). Thus, decreased taurine levels in response to folate restriction may be indicative of an overall antiproliferative effect. Interestingly, while creatine levels were decreased in all cell lines, a much greater decrease occurred in E-Wnt cells. To the best of our knowledge, creatine levels have not previously been investigated with regard to folate status. Creatine synthesis, however, might have connections to folate metabolism: glycine and SAM, required for this pathway could originate from folate metabolism (Fig. 6).

The observed changes in the pattern of major metabolites in response to folate restriction were associated with the strong inhibition of cellular proliferation, migration and invasion of mammary cancer cells. The immediate effect of folate restriction on cellular processes most likely is associated with the direct input on specific folate-dependent biochemical reactions. Thus, recent studies underscore a link between folate-dependent serine and glycine metabolism, and cellular proliferation, migration and overall aggressiveness of tumors $(6,32,52)$. Further down-stream effects could be mediated by alterations in the protein 
expression profile, a phenomenon reported previously for folate deficiency (53). In our study, folate restriction led to the decrease of levels of some folate enzymes with a more strong effect observed for SHMT1 and MTHFD1 in E-Wnt cells. Of note, MTHFD1 has previously been linked to melanoma metastasis (54). While the effect of folate withdrawal can perhaps be additionally mediated by alterations of folate enzymes, we suggest that the primary effect on cellular metabolite is due to the direct input on folate-dependent reactions. Overall, we conclude that restriction of folate in mammary cancer cells reprograms cellular metabolism towards a less proliferative or migratory phenotype, with a more profound effect exerted in cells with a mesenchymal, relative to an epithelial, phenotype. Folate restrictionrelated metabolic reprogramming may therefore represent a therapeutic target for reducing the burden of breast tumors that have undergone EMT, such as claudin-low breast cancers.

\section{Supplementary Material}

Refer to Web version on PubMed Central for supplementary material.

\section{Acknowledgments}

SAK was supported by the DK54388 grant from the National Health Institutes; SDH was supported by the CA197627 grant from the National Institutes of Health.

The authors would like to thank Dr. Silvia Gutierrez for her contributions to preliminary experiments. MH is grateful for the assistance of Daniel Bearden and Jason Winnike and benefited from helpful discussions through the course of this work.

\section{References}

1. Fox JT, Stover PJ. Folate-mediated one-carbon metabolism. Vitam Horm. 2008; 79:1-44. S0083-6729(08)00401-9 [pii]. DOI: 10.1016/S0083-6729(08)00401-9 [PubMed: 18804690]

2. Tibbetts AS, Appling DR. Compartmentalization of Mammalian folate-mediated one-carbon metabolism. Annu Rev Nutr. 2010; 30:57-81. DOI: 10.1146/annurev.nutr.012809.104810 [PubMed: 20645850]

3. Strickland KC, Holmes RS, Oleinik NV, Krupenko NI, Krupenko SA. Phylogeny and evolution of aldehyde dehydrogenase-homologous folate enzymes. Chem Biol Interact. 2011; 191(1-3):122-8. DOI: 10.1016/j.cbi.2010.12.025 [PubMed: 21215736]

4. Brosnan ME, MacMillan L, Stevens JR, Brosnan JT. Division of labour: how does folate metabolism partition between one-carbon metabolism and amino acid oxidation? Biochem J. 2015; 472(2):135-46. DOI: 10.1042/BJ20150837 [PubMed: 26567272]

5. Fan J, Ye J, Kamphorst JJ, Shlomi T, Thompson CB, Rabinowitz JD. Quantitative flux analysis reveals folate-dependent NADPH production. Nature. 2014; 510(7504):298-302. DOI: 10.1038/ nature13236 [PubMed: 24805240]

6. Tedeschi PM, Markert EK, Gounder M, Lin H, Dvorzhinski D, Dolfi SC, et al. Contribution of serine, folate and glycine metabolism to the ATP, NADPH and purine requirements of cancer cells. Cell Death Dis. 2013; 4:e877.doi: 10.1038/cddis.2013.393 [PubMed: 24157871]

7. Garcia BA, Luka Z, Loukachevitch LV, Bhanu NV, Wagner C. Folate deficiency affects histone methylation. Med Hypotheses. 2016; 88:63-7. DOI: 10.1016/j.mehy.2015.12.027 [PubMed: 26880641]

8. Chanson A, Sayd T, Rock E, Chambon C, Sante-Lhoutellier V, Potier de Courcy G, et al. Proteomic analysis reveals changes in the liver protein pattern of rats exposed to dietary folate deficiency. $\mathrm{J}$ Nutr. 2005; 135(11):2524-9. [PubMed: 16251605]

9. Leclerc D, Dejgaard K, Mazur A, Deng L, Wu Q, Nilsson T, et al. Quantitative proteomics reveals differentially expressed proteins in murine preneoplastic intestine in a model of intestinal 
tumorigenesis induced by low dietary folate and MTHFR deficiency. Proteomics. 2014; 14(21-22): 2558-65. DOI: 10.1002/pmic.201400280 [PubMed: 25081070]

10. Strickland KC, Krupenko NI, Krupenko SA. Molecular mechanisms underlying the potentially adverse effects of folate. Clin Chem Lab Med. 2013; 51(3):607-16. DOI: 10.1515/ cclm-2012-0561 [PubMed: 23241610]

11. Ward PS, Thompson CB. Metabolic reprogramming: a cancer hallmark even warburg did not anticipate. Cancer Cell. 2012; 21(3):297-308. DOI: 10.1016/j.ccr.2012.02.014 [PubMed: 22439925]

12. Amelio I, Cutruzzola F, Antonov A, Agostini M, Melino G. Serine and glycine metabolism in cancer. Trends Biochem Sci. 2014; 39(4):191-8. DOI: 10.1016/j.tibs.2014.02.004 [PubMed: 24657017]

13. Locasale JW. Serine, glycine and one-carbon units: cancer metabolism in full circle. Nat Rev Cancer. 2013; 13(8):572-83. DOI: 10.1038/nrc3557 [PubMed: 23822983]

14. Possemato R, Marks KM, Shaul YD, Pacold ME, Kim D, Birsoy K, et al. Functional genomics reveal that the serine synthesis pathway is essential in breast cancer. Nature. 2011; 476(7360):34650. DOI: 10.1038/nature10350 [PubMed: 21760589]

15. Locasale JW, Grassian AR, Melman T, Lyssiotis CA, Mattaini KR, Bass AJ, et al. Phosphoglycerate dehydrogenase diverts glycolytic flux and contributes to oncogenesis. Nat Genet. 2011; 43(9):869-74. DOI: 10.1038/ng.890 [PubMed: 21804546]

16. Vazquez A, Markert EK, Oltvai ZN. Serine biosynthesis with one carbon catabolism and the glycine cleavage system represents a novel pathway for ATP generation. PLoS One. 2011; 6(11):e25881.doi: 10.1371/journal.pone.0025881 [PubMed: 22073143]

17. Terzis AJ, Fiskerstrand T, Refsum H, Ueland PM, Arnold H, Bjerkvig R. Proliferation, migration and invasion of human glioma cells exposed to antifolate drugs. Int J Cancer. 1993; 54(1):112-8. [PubMed: 8478137]

18. Siu MK, Kong DS, Chan HY, Wong ES, Ip PP, Jiang L, et al. Paradoxical impact of two folate receptors, FRalpha and RFC, in ovarian cancer: effect on cell proliferation, invasion and clinical outcome. PLoS One. 2012; 7(11):e47201.doi: 10.1371/journal.pone.0047201 [PubMed: 23144806]

19. Green T, Chen X, Ryan S, Asch AS, Ruiz-Echevarria MJ. TMEFF2 and SARDH cooperate to modulate one-carbon metabolism and invasion of prostate cancer cells. Prostate. 2013; 73(14): 1561-75. DOI: 10.1002/pros.22706 [PubMed: 23824605]

20. Petersen LF, Brockton NT, Bakkar A, Liu S, Wen J, Weljie AM, et al. Elevated physiological levels of folic acid can increase in vitro growth and invasiveness of prostate cancer cells. BJU Int. 2012; 109(5):788-95. DOI: 10.1111/j.1464-410X.2011.10437.x [PubMed: 21771248]

21. Oleinik NV, Krupenko NI, Krupenko SA. ALDH1L1 inhibits cell motility via dephosphorylation of cofilin by PP1 and PP2A. Oncogene. 2010; 29(47):6233-44. onc2010356 [pii]. DOI: 10.1038/ onc.2010.356 [PubMed: 20729910]

22. Oleinik NV, Helke KL, Kistner-Griffin E, Krupenko NI, Krupenko SA. Rho GTPases RhoA and Rac1 Mediate Effects of Dietary Folate on Metastatic Potential of A549 Cancer Cells through the Control of Cofilin Phosphorylation. J Biol Chem. 2014; doi: 10.1074/jbc.M114.569657

23. Wang TP, Hsu SH, Feng HC, Huang RF. Folate deprivation enhances invasiveness of human colon cancer cells mediated by activation of sonic hedgehog signaling through promoter hypomethylation and cross action with transcription nuclear factor-kappa B pathway. Carcinogenesis. 2012; 33(6):1158-68. DOI: 10.1093/carcin/bgs 138 [PubMed: 22461522]

24. Dunlap SM, Chiao LJ, Nogueira L, Usary J, Perou CM, Varticovski L, et al. Dietary energy balance modulates epithelial-to-mesenchymal transition and tumor progression in murine claudinlow and basal-like mammary tumor models. Cancer Prev Res (Phila). 2012; 5(7):930-42. DOI: 10.1158/1940-6207.CAPR-12-0034 [PubMed: 22588949]

25. Krupenko SA, Oleinik NV. 10-formyltetrahydrofolate dehydrogenase, one of the major folate enzymes, is down-regulated in tumor tissues and possesses suppressor effects on cancer cells. Cell Growth Differ. 2002; 13(5):227-36. [PubMed: 12065246] 
26. Oleinik NV, Krupenko NI, Reuland SN, Krupenko SA. Leucovorin-induced resistance against FDH growth suppressor effects occurs through DHFR up-regulation. Biochem Pharmacol. 2006; 72(2): 256-66. [PubMed: 16712799]

27. DebRoy S, Kramarenko II, Ghose S, Oleinik NV, Krupenko SA, Krupenko NI. A novel tumor suppressor function of glycine $\mathrm{N}$-methyltransferase is independent of its catalytic activity but requires nuclear localization. PLoS One. 2013; 8(7):e70062.doi: 10.1371/journal.pone.0070062 [PubMed: 23936142]

28. Mishur RJ, Rea SL. Applications of mass spectrometry to metabolomics and metabonomics: detection of biomarkers of aging and of age-related diseases. Mass Spectrom Rev. 2012; 31(1):7095. DOI: 10.1002/mas.20338 [PubMed: 21538458]

29. Checa A, Bedia C, Jaumot J. Lipidomic data analysis: tutorial, practical guidelines and applications. Anal Chim Acta. 2015; 885:1-16. DOI: 10.1016/j.aca.2015.02.068 [PubMed: 26231889]

30. Limame R, Wouters A, Pauwels B, Fransen E, Peeters M, Lardon F, et al. Comparative analysis of dynamic cell viability, migration and invasion assessments by novel real-time technology and classic endpoint assays. PLoS One. 2012; 7(10):e46536.doi: 10.1371/journal.pone.0046536 [PubMed: 23094027]

31. Visentin M, Zhao R, Goldman ID. The antifolates. Hematol Oncol Clin North Am. 2012; 26(3): 629-48. ix. DOI: 10.1016/j.hoc.2012.02.002 [PubMed: 22520983]

32. Jain M, Nilsson R, Sharma S, Madhusudhan N, Kitami T, Souza AL, et al. Metabolite profiling identifies a key role for glycine in rapid cancer cell proliferation. Science. 2012; 336(6084):10404. DOI: 10.1126/science.1218595 [PubMed: 22628656]

33. Keenan MM, Chi JT. Alternative fuels for cancer cells. Cancer J. 2015; 21(2):49-55. DOI: 10.1097/PPO.0000000000000104 [PubMed: 25815843]

34. Wang H, Tso VK, Slupsky CM, Fedorak RN. Metabolomics and detection of colorectal cancer in humans: a systematic review. Future Oncol. 2010; 6(9):1395-406. DOI: 10.2217/fon.10.107 [PubMed: 20919825]

35. Hanahan D, Weinberg RA. Hallmarks of cancer: the next generation. Cell. 2011; 144(5):646-74. DOI: 10.1016/j.cell.2011.02.013 [PubMed: 21376230]

36. Rizwan A, Serganova I, Khanin R, Karabeber H, Ni X, Thakur S, et al. Relationships between LDH-A, lactate, and metastases in 4T1 breast tumors. Clin Cancer Res. 2013; 19(18):5158-69. DOI: 10.1158/1078-0432.CCR-12-3300 [PubMed: 23833310]

37. Morais-Santos F, Miranda-Goncalves V, Pinheiro S, Vieira AF, Paredes J, Schmitt FC, et al. Differential sensitivities to lactate transport inhibitors of breast cancer cell lines. Endocr Relat Cancer. 2014; 21(1):27-38. DOI: 10.1530/ERC-13-0132 [PubMed: 24174370]

38. Morais-Santos F, Granja S, Miranda-Goncalves V, Moreira AH, Queiros S, Vilaca JL, et al. Targeting lactate transport suppresses in vivo breast tumour growth. Oncotarget. 2015; 6(22): 19177-89. DOI: 10.18632/oncotarget.3910 [PubMed: 26203664]

39. Guedes M, Araujo JR, Correia-Branco A, Gregorio I, Martel F, Keating E. Modulation of the uptake of critical nutrients by breast cancer cells by lactate: Impact on cell survival, proliferation and migration. Exp Cell Res. 2016; doi: 10.1016/j.yexcr.2016.01.008

40. Kennedy KM, Scarbrough PM, Ribeiro A, Richardson R, Yuan H, Sonveaux P, et al. Catabolism of exogenous lactate reveals it as a legitimate metabolic substrate in breast cancer. PLoS One. 2013; 8(9):e75154.doi: 10.1371/journal.pone.0075154 [PubMed: 24069390]

41. Draoui N, Feron O. Lactate shuttles at a glance: from physiological paradigms to anti-cancer treatments. Dis Model Mech. 2011; 4(6):727-32. DOI: 10.1242/dmm.007724 [PubMed: 22065843]

42. Hart CD, Tenori L, Luchinat C, Di Leo A. Metabolomics in Breast Cancer: Current Status and Perspectives. Adv Exp Med Biol. 2016; 882:217-34. DOI: 10.1007/978-3-319-22909-6_9 [PubMed: 26987537]

43. Choi JS, Baek HM, Kim S, Kim MJ, Youk JH, Moon HJ, et al. HR-MAS MR spectroscopy of breast cancer tissue obtained with core needle biopsy: correlation with prognostic factors. PLoS One. 2012; 7(12):e51712.doi: 10.1371/journal.pone.0051712 [PubMed: 23272149] 
44. Kesler SR, Watson C, Koovakkattu D, Lee C, O’Hara R, Mahaffey ML, et al. Elevated prefrontal myo-inositol and choline following breast cancer chemotherapy. Brain Imaging Behav. 2013; 7(4): 501-10. DOI: 10.1007/s11682-013-9228-1 [PubMed: 23536015]

45. Serkova NJ, Gamito EJ, Jones RH, O’Donnell C, Brown JL, Green S, et al. The metabolites citrate, myo-inositol, and spermine are potential age-independent markers of prostate cancer in human expressed prostatic secretions. Prostate. 2008; 68(6):620-8. DOI: 10.1002/pros.20727 [PubMed: 18213632]

46. Croze ML, Soulage CO. Potential role and therapeutic interests of myo-inositol in metabolic diseases. Biochimie. 2013; 95(10):1811-27. DOI: 10.1016/j.biochi.2013.05.011 [PubMed: 23764390]

47. Cao MD, Sitter B, Bathen TF, Bofin A, Lonning PE, Lundgren S, et al. Predicting long-term survival and treatment response in breast cancer patients receiving neoadjuvant chemotherapy by MR metabolic profiling. NMR Biomed. 2012; 25(2):369-78. DOI: 10.1002/nbm.1762 [PubMed: 21823183]

48. El Agouza IM, Eissa SS, El Houseini MM, El-Nashar DE, Abd El Hameed OM. Taurine: a novel tumor marker for enhanced detection of breast cancer among female patients. Angiogenesis. 2011; 14(3):321-30. DOI: 10.1007/s10456-011-9215-3 [PubMed: 21553281]

49. Sitter B, Bathen TF, Singstad TE, Fjosne HE, Lundgren S, Halgunset J, et al. Quantification of metabolites in breast cancer patients with different clinical prognosis using HR MAS MR spectroscopy. NMR Biomed. 2010; 23(4):424-31. DOI: 10.1002/nbm.1478 [PubMed: 20101607]

50. Li M, Song Y, Cho N, Chang JM, Koo HR, Yi A, et al. An HR-MAS MR metabolomics study on breast tissues obtained with core needle biopsy. PLoS One. 2011; 6(10):e25563.doi: 10.1371/ journal.pone.0025563 [PubMed: 22028780]

51. Bayet-Robert M, Morvan D. Metabolomics reveals metabolic targets and biphasic responses in breast cancer cells treated by curcumin alone and in association with docetaxel. PLoS One. 2013; 8(3):e57971.doi: 10.1371/journal.pone.0057971 [PubMed: 23472124]

52. Zhang WC, Shyh-Chang N, Yang H, Rai A, Umashankar S, Ma S, et al. Glycine decarboxylase activity drives non-small cell lung cancer tumor-initiating cells and tumorigenesis. Cell. 2012; 148(1-2):259-72. DOI: 10.1016/j.cell.2011.11.050 [PubMed: 22225612]

53. Crott JW, Liu Z, Keyes MK, Choi SW, Jang H, Moyer MP, et al. Moderate folate depletion modulates the expression of selected genes involved in cell cycle, intracellular signaling and folate uptake in human colonic epithelial cell lines. J Nutr Biochem. 2008; 19(5):328-35. [PubMed: 17681772]

54. Piskounova E, Agathocleous M, Murphy MM, Hu Z, Huddlestun SE, Zhao Z, et al. Oxidative stress inhibits distant metastasis by human melanoma cells. Nature. 2015; doi: 10.1038/ nature 15726 
A

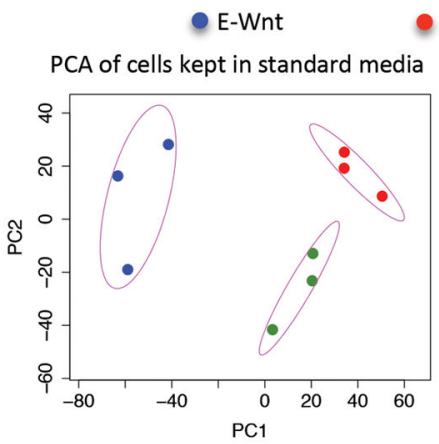

M-Wnt

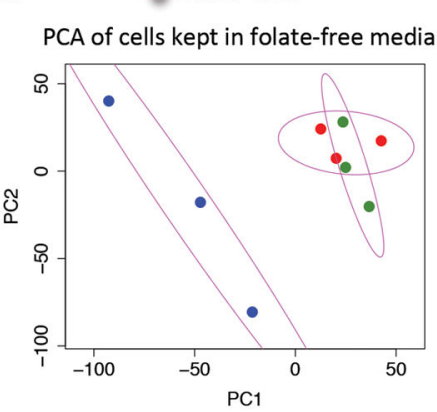

B

PCA of cells kept in standard (๑) and folate-free (@) media
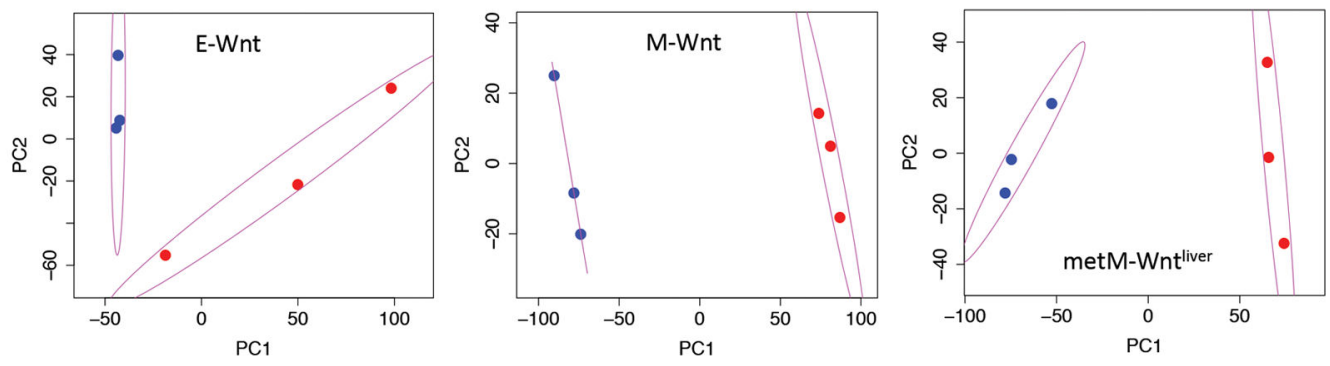

C

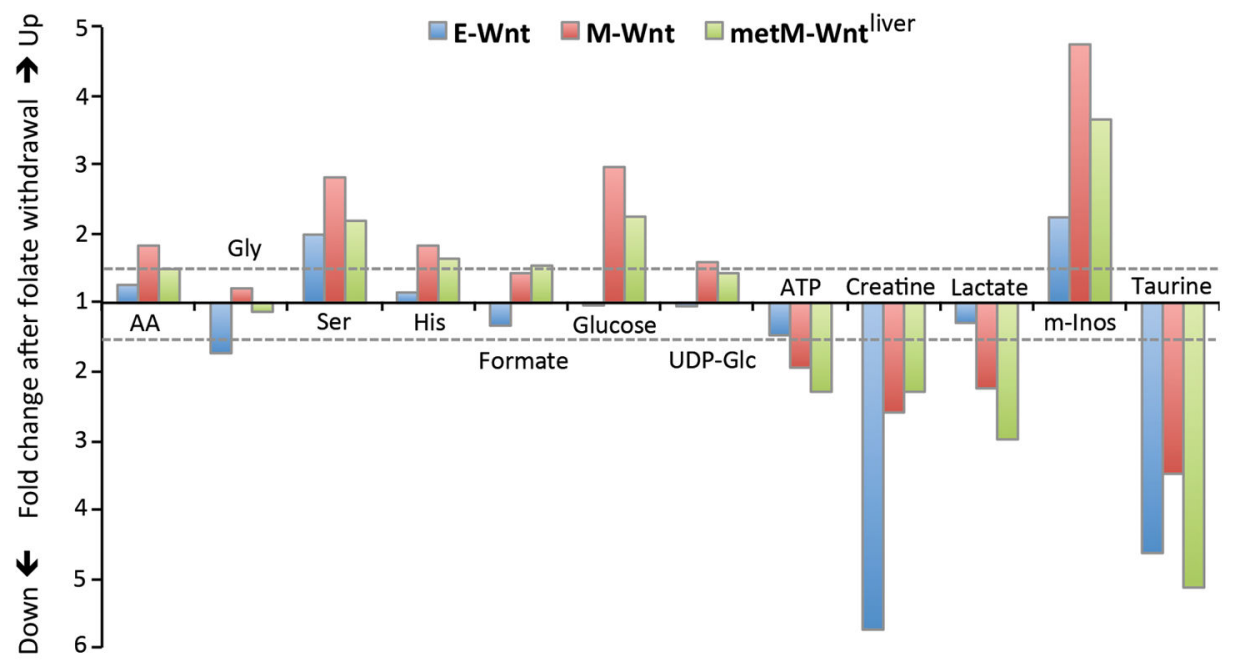

Figure 1.

Metabolic profiling of cells grown in standard (2.2 $\mu \mathrm{M}$ folic acid) or folate-free medium. A. Principal component analysis (PCA) for metabolites measured in Wnt cells by NMR spectroscopy shows how metabolically distinct are corresponding cell lines when grown in standard (left panel) or folate-free (right panel) medium. There is a good separation between cell lines when they grow in standard medium but M-Wnt and metM-Wnt ${ }^{\text {liver }}$ cell lines become metabolically indistinguishable when grown in folate-free medium. A total of 41 metabolites were measured for each of the cell lines. In order to visualize the metabolic profiles of different cell lines, principal component analysis (PCA) was carried out in the programming language $\mathrm{R}$ to reduce the dimension of the metabolic profile of each cell line. The first two principal components, i.e. PC1 and PC2, are displayed. In the PCA analysis, 
the cell line data was first mean-centered and subsequently the PCs were computed. The mean-centered data was not further scaled to obtain the $z$-score before the computation of the PCs. Ellipses are the confidence regions for the corresponding group of cell types $\mathbf{B}$. PCA shows strong differences in the metabolic profile for each cell line grown in standard vs. folate-free medium. C. Metabolites most significantly altered in Wnt cells after folate withdrawal (fold change calculated from Table 1 is shown). Dashed lines designate a threshold of 1.5-fold. AA, total amino acids; UDP-Glc, UDP-glucose; m-Inos, myo-inositol. 

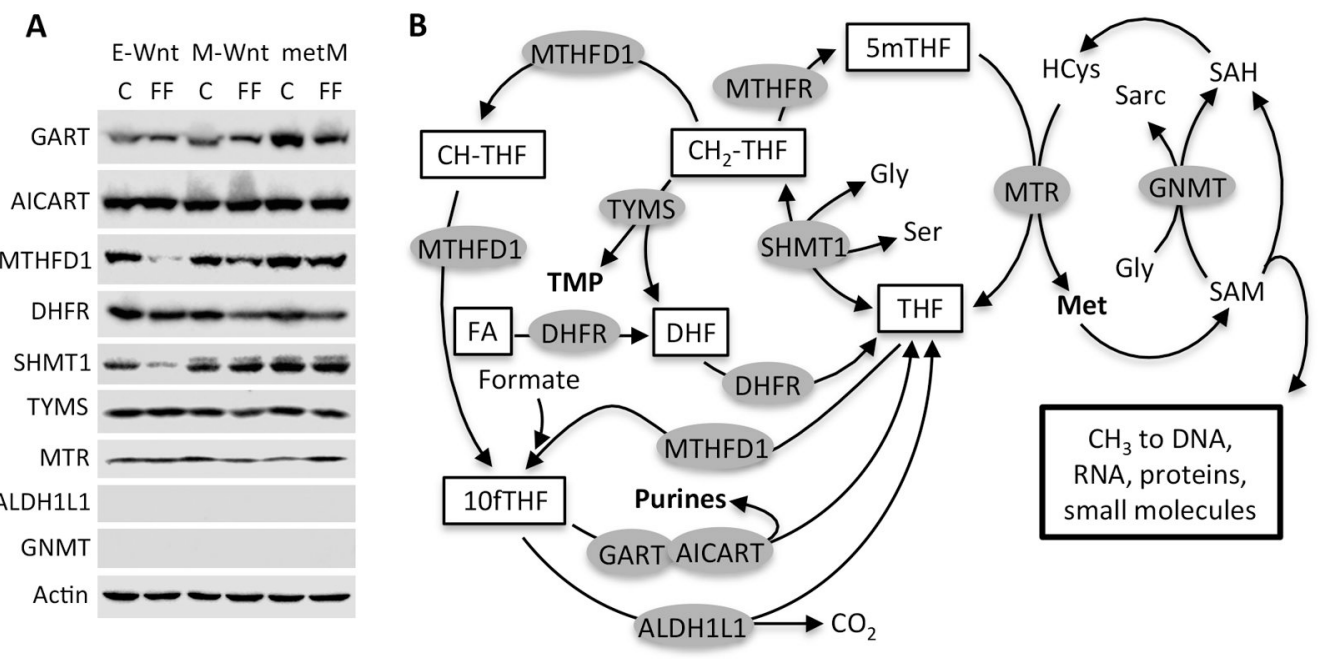

Figure 2.

Levels of folate enzymes in Wnt cells. A. Western blot assays of the level of cytosolic folate enzymes in Wnt cells grown in standard (control, $C$ ) or folate-free $(F F)$ media for $72 \mathrm{~h}$. metM, metM-Wnt ${ }^{\text {liver }}$ cells. B. Schematic depicting folate pathways and reactions catalyzed by enzymes evaluated in panel A. FA, folic acid; DHF, dihydrofolate; THF, tetrahydrofolate; 5mTHF, 5-methyl-THF; 10fTHF, 10-formyl-THF; HCys, homocysteine; Sarc, sarcosin. Enzymes catalyzing corresponding reactions are shown in grey ovals. AICART, 5aminoimidazole-4-carboxamide ribonucleotide formyltransferase; ALDH1L1, cytosolic 10formyltetrahydrofolate dehydrogenase; DHFR, dihydrofolate reductase; GART; glycinamide ribonucleotide formyltransferase; GNMT, glycine N-methyltransferase; MTHFD1, cytosolic $\mathrm{C}_{1}$-synthase; MTHFR, methylenetetrahydrofolate reductase; MTR, methionine synthase; SHMT1, cytosolic serine hydroxymethyltransferase; TYMS, thymidylate synthase. 


\section{-EWT $\square$ M-Wnt $\square$ metM-Wnt liver}
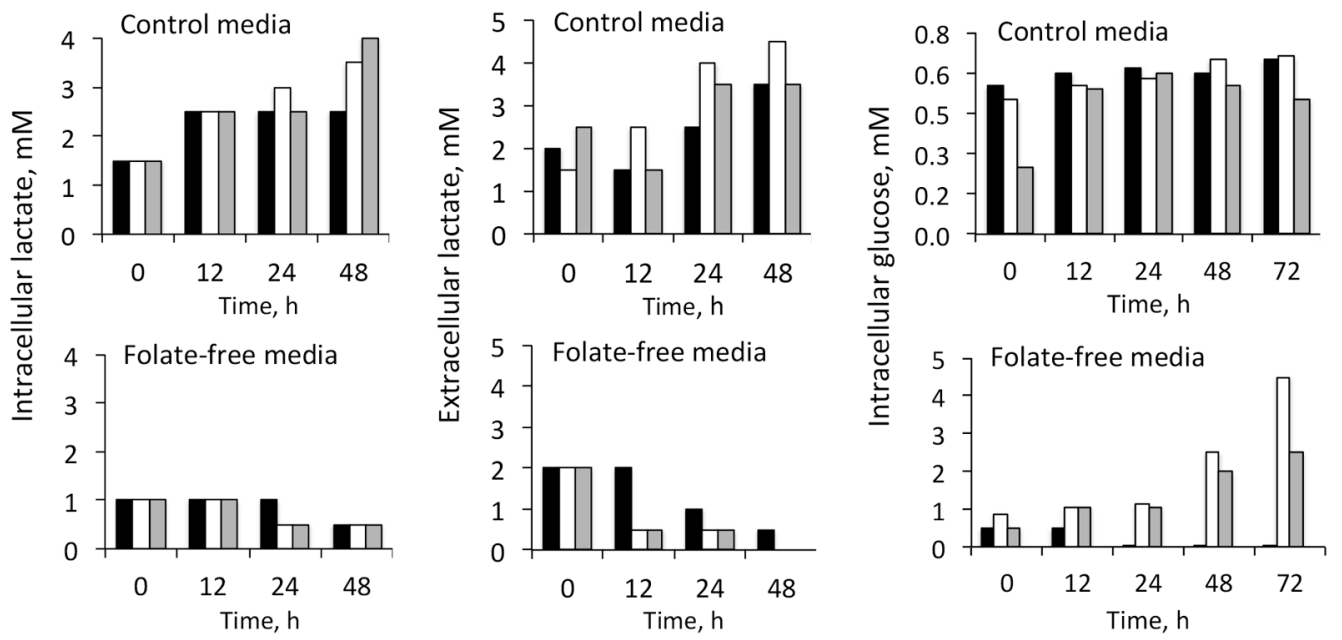

Figure 3.

Levels of glucose and lactate in E-Wnt, M-Wnt and metM-Wnt ${ }^{\text {liver }}$ cells grown in standard or folate-free medium were measured by calorimetric assays. Measurements were performed in duplicates (averages are shown). 

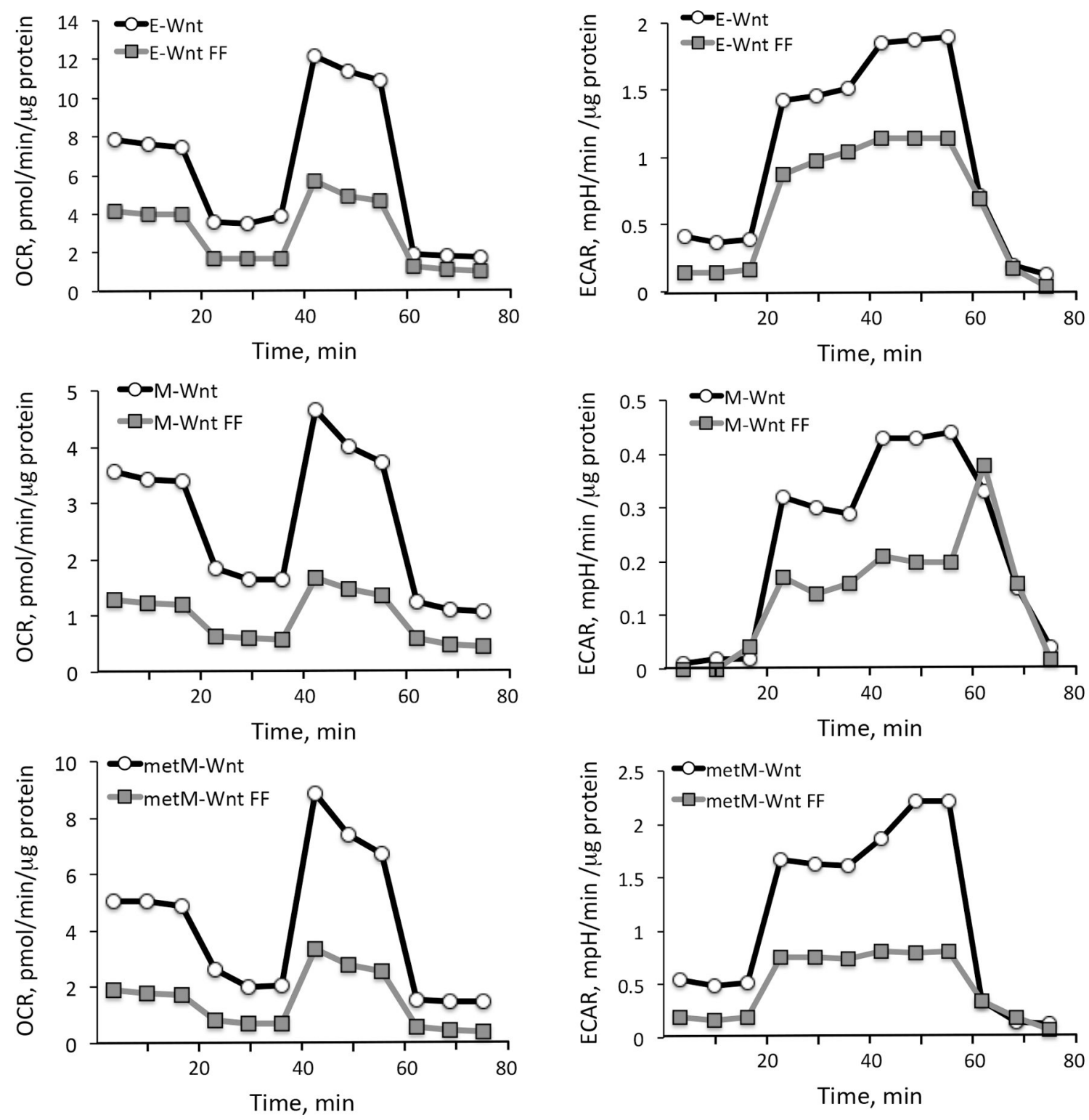

Figure 4.

Effect of folate restriction on mitochondrial respiration (oxygen consumption rate, OCR) and glycolysis (extracellular acidification rate, ECAR) of Wnt cells. A Seahorse metabolic analyzer was used to examine metabolic flux in cells. Differences for OCR between cells grown in standard and folate-free $(F F)$ media were statistically significant $(\mathrm{p}<0.001)$. Differences for ECAR were statistically significant for E-Wnt and metM-Wnt ${ }^{\text {liver }}$ cells $(\mathrm{p}<0.05)$; for M-Wnt cells $\mathrm{p}<0.14$. 
A
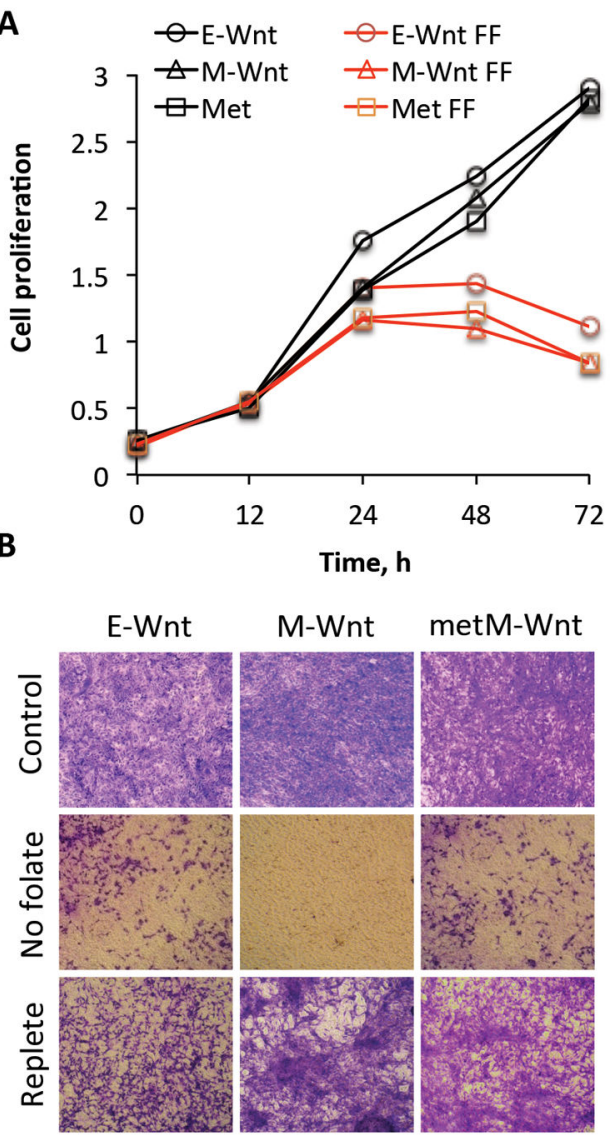

C

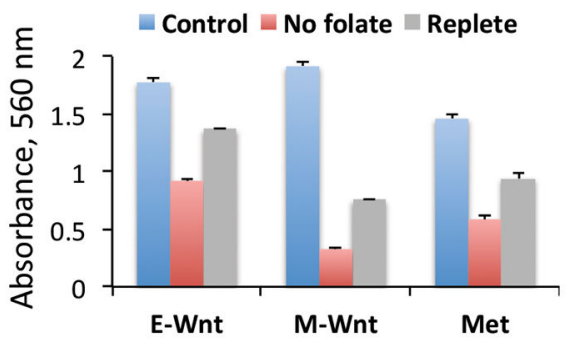

D

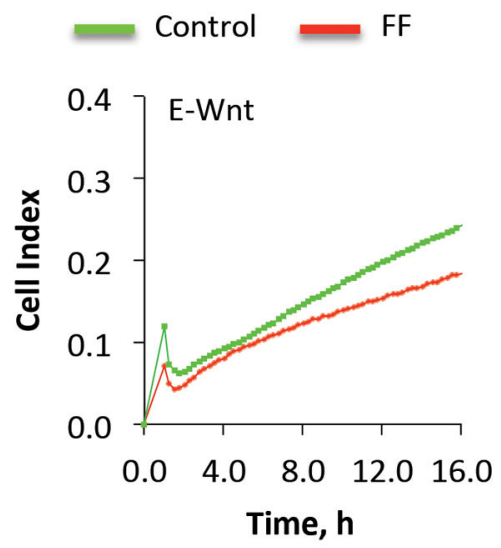

E
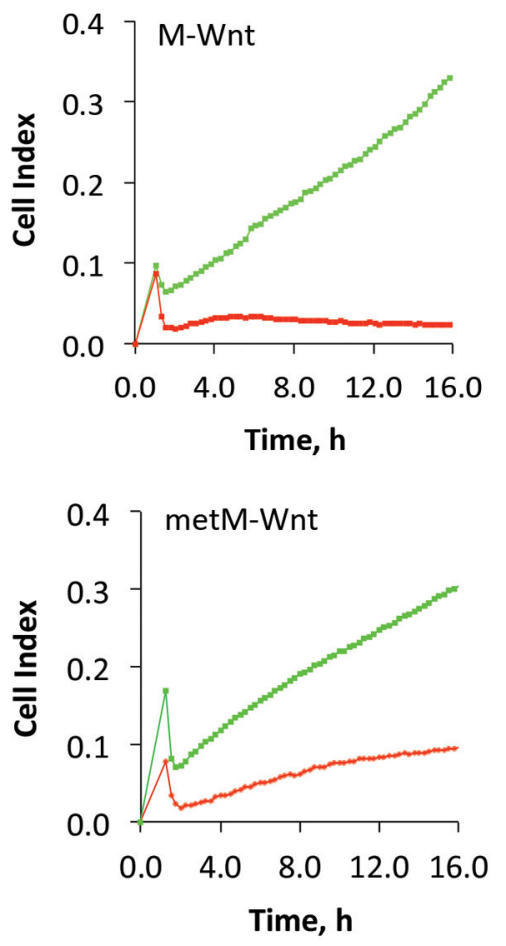

Figure 5.

Effect of folate withdrawal on proliferation, invasion and migration of Wnt cells. A. Cell proliferation was evaluated by MTT assay. (B) Invasion was evaluated by transwell assay after cells were grown in folate-free medium for $72 \mathrm{~h}$. In control experiments cells were kept in a standard ( $2.2 \mu \mathrm{M}$ folic acid) medium. In experiment with replete folate cells were kept in folate-free medium for $72 \mathrm{~h}$ and then grown in standard medium for $72 \mathrm{~h}$. Pictures show cells, which traversed through matrix. C. Calculation of cells traversed through the extracellular matrix (based on absorbance at $560 \mathrm{~nm}$ after staining with Diff-Quick dye). DF. Real-time monitoring of cellular migration using xCelligence instrument. Cell index reflects cellular migration. Experiments were performed in duplicate with automatic averaging of reading from two wells. $F F$, folate-free medium. 


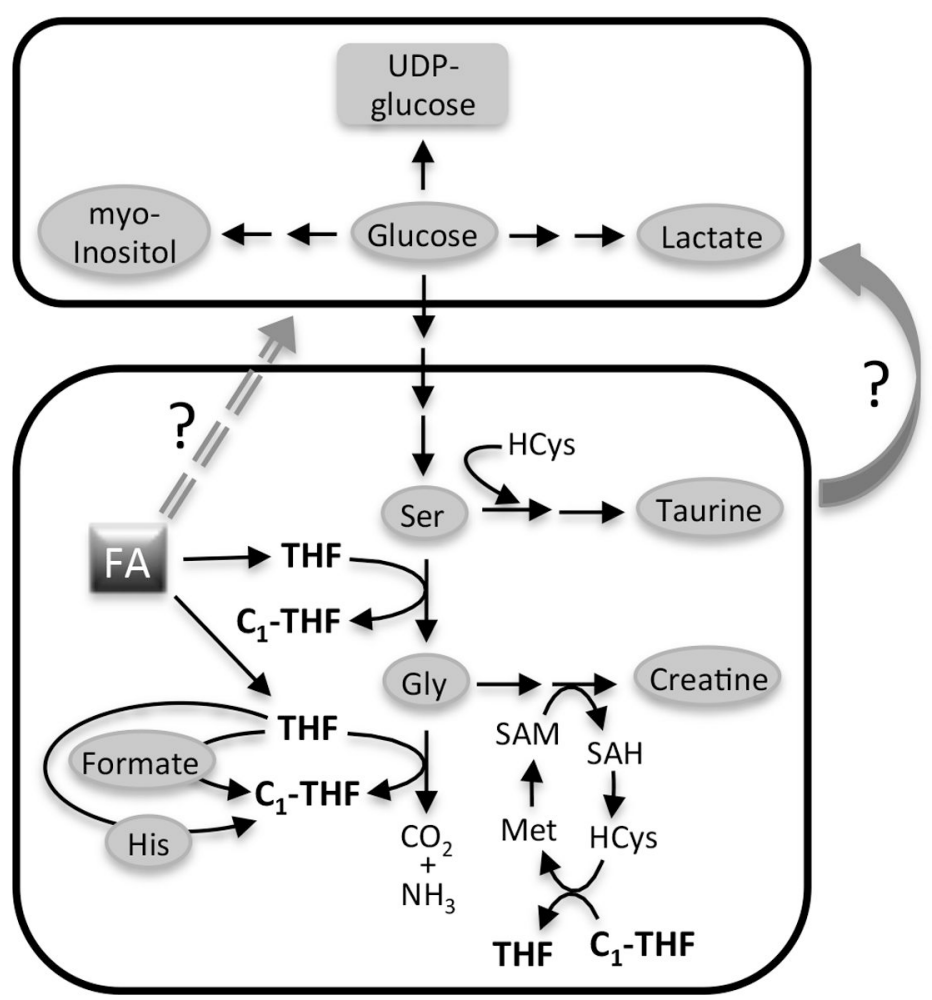

Figure 6.

Schematic depicting pathways of metabolites altered in response to folate restriction. The bottom box highlights pathways directly or indirectly associated with folate metabolism and thus expected to be responsive to folate restriction. The connection between glucose and folate metabolism is not yet established (upper box). FA, folic acid; THF, tetrahydrofolate; $\mathrm{C}_{1}$, one-carbon group; HCys, homocysteine. 


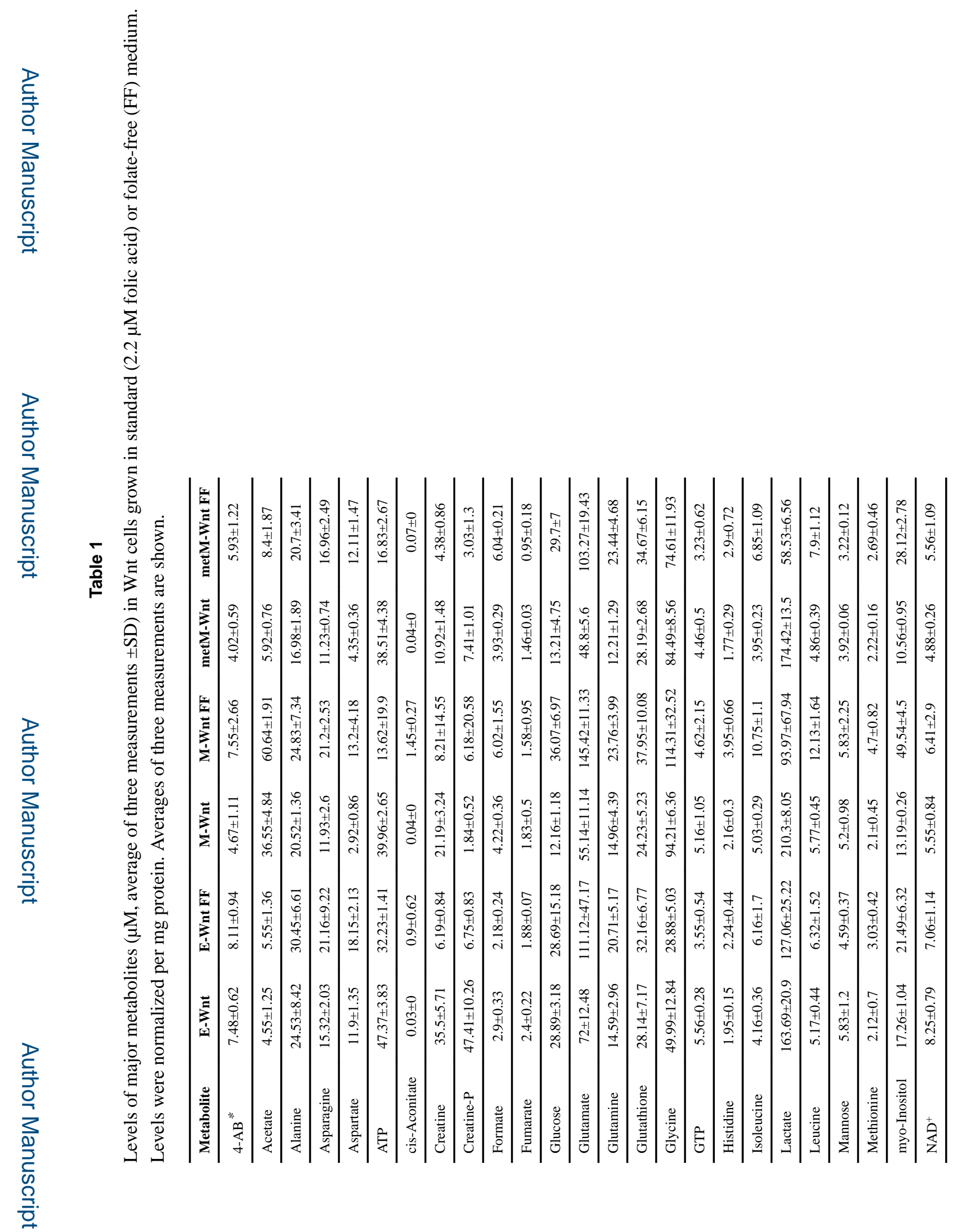

Mol Cancer Res. Author manuscript; available in PMC 2018 February 01. 


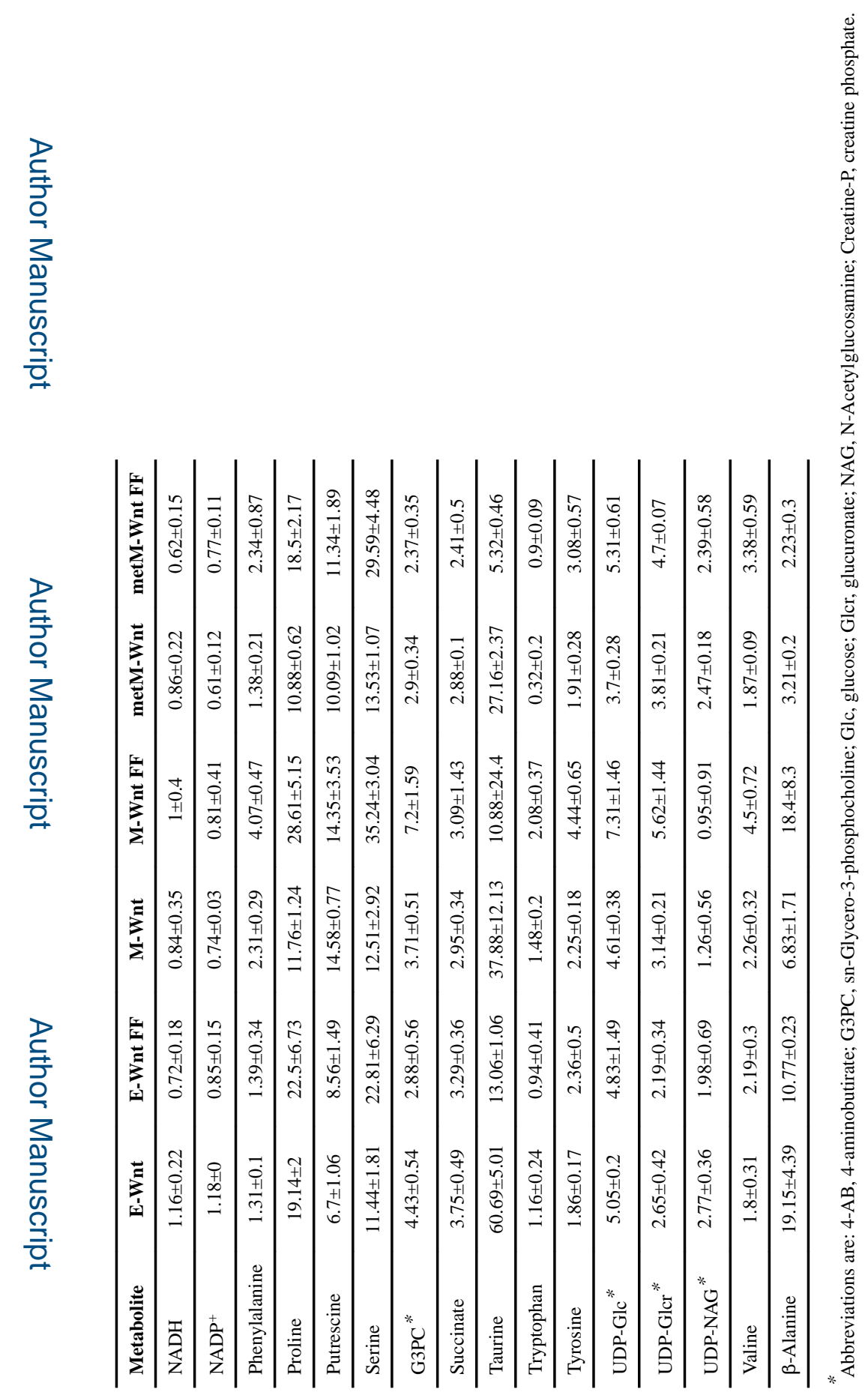

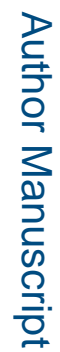

